\title{
Researching the gender division of unpaid domestic work: practices, relationships, negotiations, and meanings.
}

\begin{abstract}
The paper focuses on the potential of quantitative research methods for sociologists who research the gender division of unpaid domestic work. To begin, it reflects on the emergence of the sociological interest in unpaid domestic work and identifies an early core concern with making invisible work visible. It is argued that quantitative research methods provide us with the most valuable opportunities for 'recognising' unpaid domestic work since they facilitate larger scale representative projects. However the data in most of the large scale surveys are scant, and fail to reflect developments in the conceptualisation of unpaid domestic work. Four areas of concern to contemporary sociology are identified: domestic work practices, relationships, negotiations and meanings. Given the complex questions that these four subtopics raise, the paper proposes a range of sub-areas as a focus for ongoing sociological research into unpaid domestic work. It is concluded that despite the methodological challenges presented, detailed indicators of the multiple dimensions of unpaid domestic work need to be agreed so that valid information can be collected as routinely in large scale surveys as are those on paid work.
\end{abstract}

\section{Recognising unpaid domestic work}

The paper is concerned with how sociologists research the gender division of unpaid domestic work. First, why is this topic a concern? It is well known to readers of this journal that the contemporary sociological interest in unpaid domestic work was stimulated by second wave feminist accounts that challenged the invisibility of female-dominated domestic work within the mainstream sociology of work. Oakley's doctoral research (1974) remains a 
fascinating, influential example. In it, Oakley argued that sociology had ignored domestic work, dismissing it merely as a natural part of women's sex roles. Domestic work is a form of work, she maintained, and as such it could and should be studied sociologically.

The crux of this influential argument, that domestic work should be mainstreamed, has ramifications outside academia since it is not just sociology that has disregarded the femaledominated unpaid work that is undertaken in the home. Official statistics on work also invariably focus on its paid dimensions, with huge investment into gathering detailed and highly complex information on those working in the labour market or looking for paid work, and the characteristics of the work-place. Yet, of all the time women spend on work and study (as a main economic activity) in the UK, fully $60 \%$ is dedicated to domestic work (and $36 \%$ for men. ONS 2006: Table 4.4). Recognising the neglect of so much work in official accounts, the UN's 1993 System of National Accounts (that split unpaid work into categories according to whether or not the work is taken into consideration in systems of national accounts. SNAs), recommended that unpaid non-SNA work - including unpaid domestic work - should also be measured, accurately and regularly. In this way its contribution to total GDP can be estimated (Antonopoulos 2008). Building on this, a recent 'three r' framework for approaching unpaid work in academic debate and policy formulation, established by the United Nations Development Programme (UNDP, New York) expert group on unpaid work, time and gender, reiterates the need for more detailed information on unpaid domestic work to feed into policies to shape its 'recognition, redistribution and reduction' (Elson 2008).

If the aim is to research unpaid domestic work sociologically, in part to explore an underresearched but vital form of work, then a key stage is the operationalisation of the concept. How sociologists have approached unpaid domestic work is discussed in the next section. 
The third section of the paper then considers the potential contribution of quantitative survey methods for the study of unpaid domestic work. It reflects, in particular, on the relative neglect of domestic work from large-scale major data-sets, before going on to propose how we might approach unpaid domestic work quantitatively in future.

\section{Conceptualising unpaid domestic work}

How has unpaid domestic work been approached within sociology? Two broad influential literatures will be referred to here: the first one picking up on developments in the sociology of paid work, including emotional labour, and the second one on caring.

First then and going back to Oakley, as well as arguing powerfully for the need to recognise domestic work: to make hidden work visible, her study was also influential in sociology for taking mainstream concerns from the sociology of paid work at the time and using them to analyse the experiences of the housewives she interviewed. Oakley analysed women's domestic work conditions; work identities; job satisfaction; the monotony, pace and fragmentation of work; work routines; and autonomy, making direct reference to debates in industrial sociology at that time (see similar themes in Beynon 1973; Braverman 1974 for example).

Innovatively then, Oakley showed how women's unpaid domestic work, despite its lack of a wage relationship and its location within the private sphere, might still be analysed using the sociological concepts that emerged largely out of the study of men's paid work in the labour market. However, this emphasis on the similarities between unpaid domestic and paid work arguably served to neglect those aspects of unpaid domestic work that did not fit so well with a concept of work that was embedded in the sociology of paid work. In particular, caring 
elements of domestic practices (Chapman 2004) posed some of the deepest challenges to sociologists of work ${ }^{1}$. Indeed, a key question within the sociological study of unpaid domestic work has been whether some elements of unpaid caring should or should not be defined as part of domestic 'work'. This debate is rooted, in part, in a common conceptualisation of work as something that is transferable to others. For example, attempts to make unpaid domestic work visible in national accounts by estimating its contribution to GDP, outlined earlier, often calculate what would be the costs if domestic work tasks were outsourced to waged cleaners, cooks, and so on, using average wages rates for these occupations (Antonopoulos 2008). Given the prevalence of this transferable conceptualisation of work, it has been suggested that there are elements of unpaid caring that are not work: relationship-building caring activities that occur between a parent and child have been cited as examples here (Gray 2006; Himmelweit 1995).

The theoretical elaboration of emotional labour stands in marked contrast to a conceptualisation of domestic work that explicitly excludes elements of caring. Hochschild's (1983) The Managed Heart: Commercialization of Human Feeling famously identified a number of forms of emotional labour occurring in the workplace. She, and many others since, have shown how emotional labour is a formal part of many jobs, particularly in the service sector, and that there has been an expansion in managerial attempts to prescribe, supervise and measure its performance (Taylor 1998; Kong 2006). Accordingly, activities like 'love labour' - that might once have appeared alien to students of work in the formal wage economy - have now been conceptualised as work (Lynch 2007).

Second, an academic tradition that straddles a blurred boundary between sociology and social policy has fore-fronted an influential stream of studies specifically into understanding caring. 
What emerges from this tradition is that caring as a concept is complex, ambiguous and contested (Daly and Lewis 2000; Finch and Groves 1983; Haugen 2007; Tronto 1987, 1996). For this paper's specific focus on unpaid domestic work, it is notable that in caring: 'the distinction between work and non-work, and between paid and unpaid labour, is an especially complex one' (León 2005: 205). Daly (2002), for example, argued that caring as a concept was initially used only to depict the nature of the work involved in caring, and tended to refer mainly to care-giving work in unpaid domestic and personal services, but the concept developed to incorporate an ethic or moral orientation too (Tronto 1987, 1996; Ungerson 1983).

These literatures on unpaid domestic work and caring, located within the study of work and the study of care respectively, have begun to coalesce, for Ungerson (2005). She cites as key examples Twigg's care-based study that analyses touch during bathing in a paid care relationship, and Glucksmann's work-based research that has developed the 'total social organization of labour' concept to construe care as a form of labour too (both cited in Ungerson 2005). We can add to these a number of studies by researchers located within the sociology of the family that have led to more nuanced understandings of the meaning of unpaid domestic work for women and men. Finch's (1989) work on family obligations, for example, that examined various types of transfer within families (including economic and care transfers) asked who gives what to whom and why? Here, Finch researched how duty, obligation and responsibility are worked out within families, considering the importance of peoples' evaluations of the 'proper thing to do' and hence the ethical and moral dimensions of family obligations. Brannen and Moss (1991) amalgamated concerns with paid work, and unpaid domestic work, highlighting an interest in how couples negotiate their work-family responsibilities. Morgan's (1996) consideration of how heterosexual couples 'do gender' 
within the household also demonstrated the importance of the meaning of domestic practices within the home, showing how domestic tasks contribute to identity construction. Other discussions of gendered practices within the home (such as those by Brannen, Brannen and Moss 2004; and Chapman 2004) have laid stress on the cultural meaning of domestic practices; on allocations and expectations; on the fluidity of practices and hence the potential for change as well as the tensions existing between change and continuity, amongst other key issues.

It is apparent, then, that the sociological study of unpaid domestic work needs to build upon insights from the above influential traditions in order to properly recognise the multiple dimensions of this core concept. Four key areas of concern for sociology can be identified. These are domestic work practices (who does what); relationships (for, from and with whom); negotiations (how); and meanings of domestic work (for those carrying out domestic work and others). Given the complexities involved in researching the concept holistically in this way, what might be the potential of quantitative research methods in the further sociological exploration of unpaid domestic work?

\section{Researching unpaid domestic work: the contribution of quantitative approaches}

Many of the sociological insights into unpaid domestic work that were identified above have been gleaned from empirical studies that incorporated qualitative methodologies in some way. However, 'recognising' unpaid domestic work and making it visible also necessitates embedding questions into large scale surveys. Only in this way is it also possible to explore systematically any variations in domestic work practices, relationships, negotiations and meanings (such as by class, ethnic group, age, nation and so on), as well as to identify any changes (and continuities) over time in these four dimensions of unpaid domestic work. 
The bulk of quantitative studies of unpaid domestic work identified in a review of sociological publications in the UK over the past ten years (references not cited due to space limitations) use secondary analysis of large-scale data-sets, and the bulk focus on domestic work practices. This question is core within the study of unpaid domestic work but, even on this popular dimension, the data in major large scale studies are restricted. Secondary data analysts are invariably constrained in the variables on offer to them (Hakim 1982), but the real dearth of data on domestic work in even the largest of data-sets is stark. A prime illustrative example is the European Community Household Panel (ECHP). The ECHP is one of the largest panel surveys in Europe that provides valuable data that is at the household level, cross-nationally comparable and longitudinal. In its first wave in 1994, the sample size of the ECHP was around 60,500 nationally representative households. The data that is available on domestic work practices in the ECHP is scant. It has details on how respondents define their own main working status (with housewife/carer as an option); on whether they report carrying out unpaid housework/care; and for how many hours. There is no information at all on the topic of domestic work from some of the participating countries. In contrast, the data-set offers thirty-nine variables on employment, four on unemployment, fifteen on searching for work, twelve on previous jobs, thirty-one on training and education.

Absent or very limited data on domestic work in this and other major surveys testifies to gendered processes at work in survey design that reflect what is seen to be a suitable, serious topic for in-depth academic and policy research (Oakley 1974; Glover 1996; Spender 1980). But the advantages of secondary analysis of these types of data-sets are well recognised: offering multiple researchers access to high quality data on many thousands of respondents, with large samples providing invaluable opportunities for sub-group comparisons (Dale, 
Arber and Proctor 1988; Hyman 1972). Given the advantages of such secondary analysis, this paper considers what data a sociologist who is interested in the gender division of unpaid domestic work might like to see available. To demonstrate the possibilities, examples of relevant questions that already exist, scattered through some of the main large surveys, are drawn upon too: items specifically on domestic work as well as those on paid work that could be tweaked to asking about unpaid domestic work. The main areas of potential sociological enquiry have been grouped into the four sub-topics identified earlier: domestic work practices, relationships, negotiations, and meanings.

\section{Unpaid domestic work: Practices.}

Domestic work practices are arguably the most straightforward of the four sub-topics to research, and to do so quantitatively. However, the complexities involved in collecting data even on the routine performance of everyday tasks testify to the methodological challenges that are faced. Nine areas for questioning on domestic work practices have been proposed, below. A number of examples of actual survey questions are cited to demonstrate the possibilities (Figure 1).

i. What tasks do you carry out? Beginning with the domestic tasks that a respondent does, can we reveal the variety of tasks that are performed at the same time as seeing which ones figure most frequently in everyday life. One useful, common approach is to ask respondents to pick which tasks they usually do from a provided list (see Figure 1i), whilst the time use survey approach asks respondents to make a note of what they do during the period of the survey.

ii. How long do these tasks take? If we are interested in how domestic work impacts on lives, potentially restricting a respondent's ability to take paid work or do more paid work and/or 
rest and/or have fun and/or spend time with family and friends, we need some measurement of time committed. Assessing time spent on domestic work means asking how often tasks are performed and how long they take. Also, are tasks usual and routine or irregular? We can ask if they are performed daily (how many times per day?), weekly, monthly, annually, less often (Figure 1ii).

\section{INSERT FIGURE 1 AROUND HERE}

iii. What is the tempo or pace of the work? Is it leisurely or rushed? 'Balancing' unpaid domestic work with a job, and reconciling the needs and demands of family members, contributes to work intensity, creating a 'third shift' of work for many women (Hochschild 1989). Work intensity is an important dimension of women's domestic lives, but it is underresearched quantitatively (Floro and Marjorie 2003). Nevertheless, there are questions from surveys of paid work that target the tempo of paid work can be adapted for use (Figure 1iii).

iv. Task completion. A further temporal dimension to domestic work tasks is whether they are possible to complete in one go. From the paid work literature (e.g. Braverman 1974), we know that a completed task can provide more job satisfaction than a task which is scattered, fragmented and partial. A number of questions already exist (on unpaid domestic and paid work. Figure 1iv).

v. When are the tasks carried out? Are domestic tasks performed during the day, evening or night; during the week or at weekends? (Figure 1v). This information links us to useful debates on the negative impact of 'unsocial' work time on peoples' leisure and family lives. From the paid work literature, for example, Presser (1995) has demonstrated how unsocial 
shifts of paid work impact negatively on health and family life, whilst Warren (2003) illustrated the time poverty experienced by shift workers.

vi. Where are the tasks carried out? The location of domestic work tasks has important ramifications for the experience of doing them. Doing the laundry is an illustrative example here, with important class dimensions to it. Are clothes washed in a respondent's own home, with a washing machine? (Figure 1vi). Or has the laundry had to be collected together and carried (on foot, on public transport, in a car) to a launderette or the home of a family member/friend to use their facilities. Jarvis' (2005) geographical research identifies the classed impact of differential access to private transport on the co-ordination of households' work (see also Warren et al. 2009). TUS data provide details on where activities are carried out, but other questions exist too (Figure 1vi).

vii. What else is the person doing as they carry out that task? If multi-tasking, what are the main, secondary, tertiary activities? Multi-tasking might make an onerous task more enjoyable: watching the television while ironing as an example, but it might contribute to feelings of work intensity. Multi-tasking can also help us take into account passive domestic tasks: 'being present' while a child is at home for example (Lader et al. 2006). Linked to this, it is vital to know who is 'on call' for a task: if respondents are at a paid job, who will attend their child if $\mathrm{s} / \mathrm{he}$ is sent home sick from school/nursery or attend to a call from a sick relative? Whose sleep is disturbed by responding, or being ready to respond, to a call from someone for whom they have a caring responsibility? (Joseph et al. 2009; Venn et al. 2008). Aside from the TUS (Figure 1vii), few surveys tap into these aspects of domestic work. 
viii. Complex tasks. It has been argued that far more consideration within the analysis of unpaid domestic work is needed to the amount of unpaid planning work and mental activity that takes place within the home (Lynch 2007). It is also vital to recognise the provision of emotional support: both routine emotional support to family members as well as the extra levels of emotional support required in a time of crisis (Finch 1989). Indeed, domestic crises, and other 'big events', have received little attention in much of the quantitative research into the 'who does what/when/how long' aspects of unpaid domestic work since studies mostly tap into what people do routinely in their everyday lives. While vital, one of the limitations of a focus only on the routine and everyday is that it omits irregular but potentially major domestic work tasks. This includes the domestic work associated with potentially enjoyable big events like organising a party, visiting relatives, buying birthday presents, entertaining guests. But domestic big events can include crises that happen rarely or may never actually happen, yet might still need to be planned for. They are important to consider here too because the potential of a crisis can act as a daily stressor. A common example cited by parents is worrying what might happen if a child-care arrangement breaks down (Warren et al. 2009).

To probe such topics, 'what if' scenario tasks can be employed. Respondents can be asked to reflect back on actual 'crisis events' and/or speculate on 'what ifs'. A core 'what if' question is what happens (or what might happen) to domestic work practices if the main task do-er is taken ill. This 'key event' as trigger approach is a strategy employed usefully in quantitative research into economic well-being (McKay and Kempson 2003). Here we can ask: what happened with various domestic work tasks when ' $x$ ' happened: $x$ being the birth of an own child, if applicable for example; or when a close relative/friend had a baby; or when a close relative was sick. 
ix. Responsibility. An important elaboration of the 'who does what' question in sociology has been the exploration of 'who is responsible for what'. Some of the major surveys already examine 'who has major responsibility' for a list of domestic tasks, but being responsible for domestic work is more than just this: it can also include planning the domestic work, organizing tasks and allocating the work. Taking responsibility for, in effect being the manager of the work, involves quality control too, and so we need to know who (if anyone) sets standards; and who makes sure that the work has been done and to the right standard. Such topics appear regularly in surveys on paid work and can be adapted (Figure 1ix).

\section{Unpaid domestic work: Relationships}

i. Once we have explored who does what, a next dimension concerns the relationships between those who are doing the work and those for whom the work is being done. The core question 'who does what for whom?' reflects Finch's (1989) work into domestic transfers that asked 'who gives what to whom?'. Here, we would need to identify if domestic work is under-taken for one-self only, for someone else only, for both, or for many. Both the intraand inter-household divisions of domestic work are crucial here, and this information can also link us to debates on whether elements of domestic work are waged; whether someone receives some form of payment in kind for the work; whether there is reciprocity in work being done (Pahl 1988. Figure 2i).

INSERT FIGURE 2 AROUND HERE 
ii. While we need data on what work a respondent does for others, what respondents receive from others (or what work others do for them) must also be explored (Figure 2ii).

iii. Feeding into our analysis of the relationships involved in domestic work practices, information is needed on who is present when jobs are carried out: the 'with whom' dimension. There are two aspects to this: the first taps into whether the work is performed alone or with others; the second whether work - that is carried out alone - is undertaken while others are present. The UK TUS provides 'who is present' data (Figure 2iii).

\section{Unpaid domestic work: Negotiations}

After establishing who does and/or receives what, and for/from/with whom, a next concern is 'how' this all occurs as it does. We are interested here in negotiations: in 'working it out' (Finch 1989). Previous research, cited earlier, has shown that domestic negotiations are embedded in relationships (see point 2); that domestic practices are worked out over time; that negotiations are context specific; and that they have a moral dimension (see point 4 ). Is it possible to explore these issues quantitatively?

There are many potential questions to ask when the main concern is with the process of negotiating domestic work practices. For example: are commitments/responsibilities for domestic tasks defined, negotiated and agreed? How are standards agreed and set, if at all? Is the domestic work managed and processed? How? For example, is this on a day to day or week to week basis? Does it involve agreed or delegated job routines, job lists, requests, demands? Are there any negotiations around how practices are worked out? Wiesmann et al.'s (2008) qualitative study of Dutch couples' found that many did not consider explicitly their division of domestic work. Conversely, if negotiations are identified then what 
reasoning is employed? Magnusson (2008) shows how couples draw upon a range of discourses to support gender inequality in the home, including 'individual differences', 'sex differences', and the 'primacy of domestic peace'. So, do respondents draw upon preferences and wishes: of themselves and others in explaining their domestic work practices? Do they draw upon assumptions about sex roles; or on ideas about 'the proper thing to do'? (Ungerson 1983). Are other roles considered: for example if someone does more and/or higher waged paid work? Is competence (or perceived competence) a factor in who does what: if $\mathrm{x}$ is seen to be better at a task like ironing or cooking or putting up shelves than y. If there are negotiations, who initiates them? Is there agreement? If not, who decides ultimately?

\section{INSERT FIGURE 3 AROUND HERE}

There are some limited survey questions on domestic work negotiations already but we can also draw upon questions dedicated to how teams manage their work from workplace surveys (Figure 3).

\section{Unpaid domestic work: Meaning.}

We end with perhaps the most difficult dimension of domestic work to approach quantitatively: its meaning. Survey experts agree that variables that try to explore subjective experiences raise the most difficult measurement problems in surveys (Marsh 1982). Five sub-topics have been identified under 'meaning' here: views about the work task itself; feelings about the doing of domestic work; feelings about the division of unpaid domestic work; views on the fit between one's domestic work and the rest of life; and the moral meaning of domestic work. 
i. The task. It is uncommon to consider how various domestic tasks are perceived in general. Nevertheless, it is useful to begin by considering whether tasks are seen to be essential to domestic life or trivial (Metcalfe 2009). Are they viewed as skilled or unskilled? This information can feed into an analysis of the value attached to diverse elements of domestic work, and hence to an (under-) appreciation of the work of those who specialise in these elements (see 4ii). Pertinent examples might include views on the tasks of dusting, ironing, washing the car.

ii. Doing the task. Considering first the views of the person actually doing the work: how does their work make them feel? Do they obtain work satisfaction? Is doing domestic work felt to be a duty, an obligation, a responsibility? (Finch 1989). Is it felt to be dreary, trivial and mundane, or creative and skilled? Is it enjoyable? Is their domestic work, or elements of it, experienced as an act of love and affection? (Pahl 1988). Does the respondent feel that their work is noticed? Women in numerous qualitative studies report that the domestic work that they do for others remains invisible to and un-appreciated by family members, conversely men who do domestic work are often highly praised (Hochschild's 1989 notion of an economy of gratitude; Brannen and Moss 1991). Do respondents feel that their work is appreciated, and do they feel that others are grateful for their work? Is appreciation important to the respondent? Finally, do respondents' feelings about their domestic work vary depending on context (if a task is carried out for a special occasion for example?).

Next, it is important though rare to also consider the attitudes and feelings of those for whom domestic work is done. As above, do these respondents 'see' and appreciate the work that is done for them? Is the work carried out on their behalf seen to be trivial or important? Is its quality deemed satisfactory? In numerous qualitative accounts, women are reported to be 
critical of the quality of the work (such as cleaning and ironing) that their male partners have undertaken (Brannen and Moss 1991; Charles and James 2005; Metcalfe 2009).

\section{INSERT FIGURE 4 AROUND HERE}

iii. The division of unpaid domestic work. Are arrangements and practices seen to be fair? Concepts like fairness and equality in the study of unpaid domestic work, as elsewhere, are complex to research (Nordenmark and Nyman 2003). Nevertheless, this is a core sociological interest since women and men are expressing increasing support for the idea of more gender equality in domestic work practices but the lived reality lags behind the rhetoric (Fox et al. 2009).

First, in respondents' views, is there a fair exchange of tasks in their own home? Who 'does' versus who 'should'? Is work seen to be reciprocal? Is reciprocity important? (4iii). Studies have shown that actual hours committed to domestic work by partners is less important in 'partnership satisfaction' than perceptions of fairness (Wilkie et al. 1998). Second, is the division of domestic work seen to be fair in society in general? (4iii). Respondents' views on general statements, that are explored commonly in surveys, can be employed here (see $4 \mathrm{v}$ ). Hakim $(2000,2003)$ warns against confusing individuals' personal lifestyle preferences with their approval or disapproval of general attitude statements.

iv. Work-life reconciliation. Do the respondents' feel that their unpaid domestic work fits together smoothly with the rest of their lives? Do they feel that they have enough time to do

what they need or want to, in terms of family life, leisure, community participation, and so on. Or does one domain of their lives spill-over and impact negatively on others? (Dilworth 2004). Do they worry about 'balancing' or reconciling paid and unpaid domestic work, if 
applicable? Do they experience the stress and hard work of a third shift? A large number of surveys already ask a range of useful questions about work-life balancing (Figure 4iv), and quality of life is researched quantitatively widely too (see Phillips 2006).

v. The moral meaning of domestic work. Literatures on caring and care work and on paid work have asserted that 'what you do' in terms of work shapes 'who you are'. The moral dimension to domestic negotiations and the 'ethic of care' are also linked firmly to identity construction. Domestic practices often reflect what seems right in given conditions, and what is seen as the proper thing to do. Moreover these practices are known to be gendered (as well as classed and racialised. Duncan 2005). For Morgan (1996), for example, vacuuming, from one perspective, can be seen to be necessary for keeping the home clean and so can be performed by anyone. From a gender perspective, however, doing vacuuming is a way of 'doing gender'. For women, studying their domestic work thus connects us to key ideas about being a good woman/mother/partner. It also links us to classed debates about being respectable (Skeggs 1987). It is vital then to interrogate normative rules, and variations in these, around domestic work to consider what people feel that they should do, and to identify any differences between 'the ought' and 'the is': between beliefs and actions (Finch 1989). Examining peoples' interpretations of 'the normative' in terms of domestic work, and their own stances on it, is valuable for allowing us to identify similarities and differences in domestic working in diverse cultural settings.

Looking at normative views, a number of surveys ask respondents to agree/disagree with general statements on the division of domestic work. And, since individuals' own preferences should not be conflated with their approval or disapproval of general attitude statements, we should look to personal preferences too (Figure 4v). 
Finally, how are these attitudes to unpaid domestic work shaped? There is little quantitative information on this currently. However, respondents could be asked, as an example, to reflect on their own domestic work practices and to consider whether the views and domestic practices of their parents have impacted their own lives. They could be asked if they are aware of the domestic practices of their friends and peers (Metcalf 2009), and whether they compare these with their own. Where applicable, too, do their children undertake domestic work, and do respondents feel it is important to teach children about doing domestic work. In household surveys in which children are also interviewed about domestic work (such as the BHPS), parental and children's views on domestic work can be compared.

\section{Conclusion}

The paper has been concerned with a significant but under-researched area of work: the unpaid domestic work that is carried out in the home, mainly by women. It has been argued that a commitment to making this 'hidden' work visible, to 'recognising' it, is best facilitated by research that employs large scale survey methods. These methods are vital for the identification of patterns and trends in the gendering of unpaid domestic work, as well as for uncovering diversity amongst social groups by class, ethnic group, age, region, country, and so on. A wealth of information has been collected by quantitative sociological studies of unpaid domestic work, but most have focused on domestic work practices. The potential for large-scale quantitative research into even just this one dimension of unpaid domestic work has been restricted by the paucity of relevant data in the major data-sets. It has been argued that it is vital that unpaid domestic work is quantified more thoroughly so that information can be collected for detailed comparative studies, as well as for explorations across time (and see Warde and Hetherington 1993). 
A review of data available in the large data-sets re-affirmed the value of some sources. Time use surveys, for example, offer detailed information on many aspects of the 'domestic work practices' research questions. The British Time Use Survey, for example, asks respondents to complete two 24-hour diaries, which are broken down into ten minute slots (Short 2006). The survey also has a Child Questionnaire. Strengths of a time use survey for the analysis of unpaid domestic work include allowing researchers to identify a vast number of tasks as well as recording simultaneous activities. The British survey also provides information on where the activity occurred, the presence of other people, and for who the activity was carried out. However, information on negotiations and meanings of domestic work practices are lacking. Given the narrow, though detailed and valuable, information on practices, Time use surveys that have been designed to act as separate but linked modules within broader household surveys offer great potential. Many national household surveys already include questions on who performs a number of routine domestic tasks, as well as who provides the bulk of any care work for children and elderly family members. The most useful large surveys include a panel element to facilitate longitudinal analysis too, feeding into key questions of change and continuity (see the British Household Panel Survey, now incorporated into the UK Household Longitudinal Study).

Unfortunately, few household surveys reflect developments in the conceptualisation of unpaid domestic work and no survey provides enough detail for a comprehensive analysis of unpaid domestic work using the 'practices, relationships, negotiations, and meanings' framework proposed in this paper. Indeed, remembering the neglect of unpaid domestic work in the ECHP, it might seem laughable to argue for a full module on unpaid domestic work that would incorporate these four dimensions and that would total eighteen sub-topics at least, 
running easily to one hundred questions. But if quality surveys, like the UK Longitudinal Study, are fully committed to covering 'every important aspect of who we are and how we live' (Understanding Society 2008), far more detailed attention to unpaid domestic work is essential.

The paper has focused on the potential of large scale quantitative methods for sociological research into unpaid domestic work, but employing a range of methods can of course offer the most fruitful of approaches for researching a topic holistically. A multi-methods strategy offers advantages in terms of answering complementary questions about unpaid domestic work, for enhancing the interpretability of results and providing better opportunities to explore their validity (Denzin 1978; Robson 1993). Hence, the main research questions identified above, under the 'practices, relationships, negotiations, and meanings' framework, can also be employed in qualitative (and mixed methods) studies. In this way, in-depth information on unpaid domestic work would be collected to complement the broader findings that result from large-scale surveys.

The main conclusion of the paper then is that what is needed is more debate over how we can develop well-operationalised multiple indicators for sociological research into unpaid domestic work. Far more discussion is due amongst sociologists over what elements of domestic work practices, relationships, negotiations, and meanings should and can be explored quantitatively, and how.

\section{Appendix. The surveys providing sample questions for Figures 1-4.}

BHPS British Household Panel Survey; BSA British Social Attitudes Survey; ECHP European Community Household Panel Survey; ECWS European Working Conditions 
Survey; EQLS European Quality of Life Survey; ESS European Social Survey (various rounds); ISSP International Social Survey Programme (third module on Family and Changing Gender Roles); MACA Multidimensional Assessment of Caring Activities; MWLB the Work Foundation's manual on work-life balance; PANOC Positive and Negative Outcomes of Caring; TUS UK Time Use Survey; WERS Workplace Employee Relations Survey; YPSAS Young People's Social Attitudes Surveys.

\section{References}

Antonopoulos, R. (2008) ‘The Unpaid Care Work-Paid Work Connection’, Working Paper No. 541, New York: The Levy Economics Institute.

Beynon, H. (1973) Working for Ford, Middlesex: Penguin.

Brannen J and Moss P (1991) Managing Mothers: Dual Earner Households After Maternity Leave London: Unwin Hyman Ltd

Brannen, J., Brannen, A., and Moss, P. (2004) Working and Caring over the Twentieth Century: Change and Continuity in Four Generation Families, Basingstoke: Palgrave.

Braverman, H. (1974) Labour and Monopoly Capitalism: the Degradation of Work in the Twentieth Century, New York: Monthly Review Press.

Charles, N. and James, E. (2005) "“He earns the bread and butter and I earn the cream": job insecurity and the male breadwinner family in South Wales', Work, Employment and Society, 19(3): 481-502.

Dale, A., Arber, S. and Proctor, M. (1988) Doing Secondary Analysis, London: Unwin Hyman.

Daly, M. \& Lewis, J. (2000) 'The concept of social care and the analysis of contemporary welfare states', British Journal of Sociology, 51 (2) 281-298. 
Daly, M. (2002) 'Care as a good for social policy', Journal of Social Policy, 31 (2) 251-270.

Denzin, N. (1978) Sociological Methods: A Sourcebook, New York: McGraw Hill.

Duncan, S. (2005) 'Mothering, class and rationality, Sociological Review, 53, 2, 50-76.

Elson, D. (2008) Recognition, Redistribution and Reduction, Presentation at launch of UNDP Expert Group on Unpaid Work, Gender and the Care Economy, November, New York: UNDP.

Finch, J and Groves, D. (1983)(eds.) A Labour of Love: Women, Work, and Caring, London: Routledge \& K. Paul.

Finch, J. (1989) Family Obligations and Social Change Cambridge: Polity Press

Floro, M.S. and Marjorie M. (2003). 'Time use, work, and overlapping activities: evidence from Australia', Cambridge Journal of Economics, 27(6): 881-904.

Glover, J. (1996) 'Epistemological and methodological considerations in secondary analysis' in

L. Hantrais and S. Mangen (eds.) Cross-national Research Methods in the Social Sciences, London: Pinter.

Gray, A. (2006) 'The time economy of parenting', Sociological Research Online, 11, 3, $<$ http://www.socresonline.org.uk/11/3/gray.html $>$..

Hakim, C. (1982) Secondary Analysis in Social Research: a guide to data sources and methods with examples, London: Allen and Unwin.

Hakim, C. (2003) 'Public Morality Versus Personal Choice: The Failure of Social Attitude Surveys', British Journal of Sociology, 53(3): 339-46.

Haugen, G.M.D. (2007) 'Caring children: exploring care in post-divorce families', The Sociological Review, 55, 4: 653-670.

Himmelweit, S. (1995) 'The discovery of unpaid work; the social consequences of the expansion of work', Feminist Economics, 1, 2: 1-20. 
Hochschild, A. (1983) The Managed Heart: Commercialisation of Human Feeling London: University of California Press.

Hochschild, A. (1989) The Second Shift: Working Parents and the Revolution at Home, New York: John Wiley.

Hyman, H. (1972) Secondary Analysis of Sample Surveys, New York: Wiley.

Jarvis, H. (2005) 'Moving to London Time Household co-ordination and the infrastructure of everyday life', Time and Society, 14(1), 133-154.

Joseph, S., Becker, F. and Becker, S. (2009)Manual for Measures of Caring Activities and Outcomes for Children and Young People. London: The Princess Royal Trust for Carers.

Lader, D. Short, S. and Gershuny, J. (2006) The Time Use Survey, 2005, How we spend our time, London: ONS

León, M. (2005) 'Welfare State regimes and the social organization of labour: Childcare arrangements and the work/family balance dilemma', The Sociological Review, 53, 2: 204-218.

Lynch, K. (2007) 'Love labour as a distinct and non-commodifiable form of care labour', The Sociological Review, 55, 3: 550-570.

Magnusson, E. (2008) 'The Rhetoric of Inequality: Nordic Women and Men Argue against Sharing House-work', NORA - Nordic Journal of Feminist and Gender Research, 16, $2: 79-95$.

McKay, S. and Kempson, E. (2003) Savings and Life Events (Department for Work and Pensions Research Report number 194), Leeds: Corporate Document Services.

Metcalfe, G. (2009) 'A class and gendered explanation of an unequal domestic division of labour', Unpublished paper. 
Morgan, D. (1999) 'Gendering the Household: Some Theoretical Considerations' in L. McKie, S. Bowlby \& S. Gregory (eds.) Gender, Power and the Household London: Macmillan Press pp. 22-40.

Nordenmark, M. and Nymann, M. (2003). 'Fair or Unfair? Perceived Fairness of Household Division of Labour and Gender Equality among Women and Men. The Swedish Case', European Journal of Women's Studies, 10, 2, 181-209.

Oakley, A. (1974) The Sociology of Housework London: Penguin

Office for National Statistics (ONS) (2006). The Time Use Survey, 2005. How We Spend our Time, London: HMSO.

Pahl, R. (1988) On Work, Oxford: Blackwell.

Phillips, D. (2006) Quality of Life. Concept. Policy and Practice, Abingdon: Routledge.

Robson, C. (1993) Real World Research: A Resource for Social Scientists and PractitionerResearchers, Oxford: Blackwell.

Short, S. (2006) Review of the UK 2000 Time Use Survey, London: Office for National Statistics.

Skeggs, B. (1997) Formations of Class and Gender: Becoming Respectable, London: Sage. Spender, D. (1980) Man Made Language, London: Routledge \& Kegan Paul. Tronto, J.C. (1987) 'Beyond gender difference to a theory of care', Signs, Within and Without: Women, Gender, and Theory, 12, 4, 644-663.

Tronto, J.C. (1996). 'Care as a political concept', in N. Hirschmann. and C. Di Stefano (eds.) Revisioning the Political: Feminist Reconstructions of Traditional Concepts in Western Political Theory, Oxford: Westview Press.

Understanding (2008) What do we study http://www.understandingsociety.org.uk/overview/whatis/issues.aspx, accessed 6 July 2009. 
UN (1993) About the System of National Accounts 1993 http://unstats.un.org/unsd/sna1993/introduction.asp, Consulted 2 April 2009. UN (2005) Guide to Producing Statistics on Time Use. Measuring Paid and Unpaid Work. Department of Economic and Social Affairs, New York.

Ungerson, C. (1983) 'Why do women care' in Finch, J. \& Groves, D. (eds.) A Labour of Love. Women, Work and Caring, London: Routledge and Kegan Paul.

Ungerson, C. (2005) 'Care, work and feeling', The Sociological Review, 53 (s2), 188-203. Venn, S., Arber, S., Meadows, R. and Hislop, J. (2008) 'The fourth shift: Exploring the gendered nature of sleep disruption in couples with children', British Journal of Sociology, 59(1): 79-90.

Warde, A. and Hetherington, K. (1993) 'A changing domestic division of labour? Issues of measurement and interpretation', Work, Employment and Society, 7, 1, 23-45.

Warren, T. (2003) 'Class- and gender-based working time? Time poverty and the division of domestic labour', Sociology, 37, 4, 733-754.

Warren, T., Pascall, G and Fox, E. (2009) 'Innovative social policies for gender equality from Europe: implications for the work-life reconciliation of low waged women in England', Gender, Work and Organization. Special issue: Work/Life Balance: A Matter Of Choice?, 16, 1, 126-150..

Wiesmann, S., Boeije, H., van Doorne-Huiskes, A. den Dulk, L. (2008) 'Not worth mentioning': The implicit and explicit nature of decision-making about the division of paid and domestic work', Community, Work \& Family, Volume 11, Issue 4, 341 363.

Wilkie, J. R., Ferree, M. M., \& Ratcliff, K. S. (1998). 'Gender and fairness: marital satisfaction in two-earner couples', Journal of Marriage and the Family, 60, 577-594. 